\title{
AN EARLY DIAGNOSTIC SYMPTOM IN CHRONIC INTUSSUSCEPTION
}

\author{
ANDREW M. MunSTER, F.R.C.S., F.R.C.S.(Ed.) \\ Surgical Registrar, General Hospital, Rochford, Essex.*
}

THE clinical diagnosis of chronic intussusception in adults is notoriously difficult. Unless a mass is palpable in the abdomen, or the intussusception reveals itself on rectal examination, there may be little more to go on than vague abdominal pain and indefinite signs. Preoperative diagnosis is rarely made; out of 28 cases of spontaneous sloughing and healing collected by Robb and Souter (1962), only three were diagnosed before operation. In more than half of all patients, symptoms go on for over three months before diagnosis is reached (Bond and Roberts, 1964), and should there be an underlying benign tumour, the length of time before detection may average fifteen months (Sanders, Hagan and Kinnaird, 1958).

Nevertheless, early diagnosis is important for a number of reasons. A third of all cases have an underlying malignancy (Sanders and others, 1958). Furthermore, intussusception in its fully developed form is a strangulation obstruction (Roper, 1956), and its prognosis correspondingly worse. Lastly, if chronic intussusception due to carcinoma is recognised early, the prognosis is better than in uncomplicated caroinoma, as intussusception implies mobility and a long, unfixed mesentery. (Teasdale, 1953).

Three cases of adult intussusception have been seen at the General Hospital, Rochford, in the past year. All had one striking symptom in common: that of colicky abdominal pain within an hour or two of eating, not relieved by alkalis, and made worse by food or drink. In all three cases at some stage the diagnosis of peptic ulcer was mistakenly made.

\section{Case no. 1}

Female, aged 27 years. Presented with three months' history of central abdominal pain and vomiting coming on two hours after eating, and not eased by antacids. Bowel actions had been regular. Eventually the patient became "afraid to eat", and lost a great deal of weight. There were no relevant findings on physical examination. Finally, complete small bowel obstruction developed. Laparatomy revealed a tumour of the ileum, $7 \mathrm{~cm}$. from the ileocaecal valve, which had intussuscepted into the ascending colon. Following right hemicolectomy, the patient made a good recovery. Pathology showed lymphosarcoma, with widespread glandular involvement.

*Present address:

Pcter Bent Brigham Hospital, Boston 15, Mass., U.S.A.
Case no. 2

Female, aged 56 years. First seen six months before operation, when she gave a history of griping abdominal pain for three months, made worse by food and cold drink. The bowels had acted normally throughout. Barium meal and barium enema investigations were normal. She was given a gastric diet, propantheline and belladonna for six months, but symptoms persisted. Laparotomy, nine months after the onset of symptoms, revealed a tumour of the ileocaecal valve intussuscepting into the ascending colon. She made a good recovery following right hemicolectomy. Pathology showed a mucus-secreting adenocarcinoma which had penetrated the muscle wall, with wide glandular involvement.

\section{Case no. 3}

Female, aged 85 years. She had had epigastric pain following the intake of food over the period of a year, and occasional diarrhoea. She had been treated at home on a gastric regime until continuing loss of weight had prompted investigation. Examination revealed an epigastric mass, and barium enema showed an obstruction in the transverse colon. She made an uneventful recovery following right hemicolectomy for an intussuscepted carcinoma of the ileocaecal valve. Pathology showed an adenocarcinoma with lymphatic involvement.

\section{Discussion}

Despite the voluminous literature on the subject, particularly of recent years the symptom of pain after meals is only sporadically mentioned. However Burmeister (1962) elicited this symptom in eight out of twelve patients with ileocolic intussusception, and goes as far as to state that even benign tumours, when intussuscepting, give rise to extensive weight loss, possibly related to an aversion to food and water because of accentuation of pain or fear of it.

In physiological terms, this symptom of colicky abdominal pain one to two hours after meals can be explained on the basis of the gastrocolic reflex. Increased peristalsis following the introduction of food into the stomach will cause a tumour to be driven along the bowel as an intussusception, which will cause a temporary obstruction. Spontaneous reduction occurs once the reflex has ceased.

It appears, therefore, that repeated attacks of colicky abdominal pain (and perhaps vomiting) having a constant time relationship to meals may be a valuable early symptom of intussusception, and should be investigated by repeated abdominal examination and barium enema.

\section{Summary}

1. Colicky abdominal pain coming on after the intake of food and drink may be an early symptom of chronic intussusception in adults. 
2. Early diagnosis and treatment are important. 3. Three new cases are reported.

I would like to express my gratitude to Mr. B. J. Sanger and Mr. A. G. Dingley, the Consultant Surgeons under whose care these patients had been admitted, for permission to publish this report and for valuable advice and criticism.

\section{REFERENCES}

BOND, M. R., and RoBerTS, J. B. M. (1964): Intussusception in the Adult, Brit. J. Surg., 51, 818.
Burmeister, R. W. (1962): Intussusception in the $\frac{2}{3}$ Adult: An Elusive Cause of Recurrent Abdominal Pain, Amer. J. Dig. Dis., 7, 361.

RobB, W. A. T., and SouTER, W. (1962): Spontaneous $c$ Sloughing and Healing of Intussusception, Brit. J. $\overrightarrow{\vec{F}}$ Surg., 49, 542.

ROPER, A. (1956): Intussuscention in Adults, Surg. Gynec. Obstet., 103, 267.

Sanders, G. B., Hagan, W. H., and Kinnaird, D. W. (1958): Adult Intussusception and Carcinoma of ${ }^{\mathbb{\Phi}}$ the Colon, Ann. Surg., 147, 796.

Teasdale, D. H. (1953): Colo-colic Intussusception in the Adult, Brit. J. Surg., 41, 128.

\title{
A CASE OF MUNCHAUSEN'S SYNDROME PRESENTING AS RENAL COLIC
}

\author{
Roger SANDERS, B.M., B.Ch. \\ The Radcliffe Infirmary, Oxford.
}

Munchausen's syndrome is usually divided into three varieties; the abdominal, neurological and haemorrhagic types (Asher, 1951). The abdominal category classically presents with many abdominal incisions and a florid history.

Recently a case presented at the Radcliffe Infirmary who had but one incision, and described symptoms of a condition not previously associated with Munchausen's syndrome.

\section{Case Report}

A gloomy, solitary man of 42, M.T., presented at the Casualty Department, Radcliffe Infirmary, claiming that whilst driving his removal van through Oxford on a journey from Leicester to Bristol, he was doubled up with pain in his left loin, radiating down to his penis. The pain recurred at ten-minute intervals, and was associated with dysuria. On examination, he appeared tender over the left kidney. A tentative diagnosis of renal colic was made, and he was given pethidine, $100 \mathrm{mg}$. on 13 occasions. Emergency pyelogram, blood urea and midstream specimen of urine were all normal. After a week, the character and site of his pain changed, and he now appeared tender over the 12th dorsal vertebra. A "disc lesion" was suspected, and he was referred to an orthopaedic surgeon, who encased him in a plaster jacket. The following day, his pain was far more severe, and he appeared for once to be in real agony. It was decided to transfer him to an orthopaedic hospital and place him on traction.

As he seemed little distressed by the pain, which usually occurred when no doctors were present, a letter was sent to his local practitioner to find out more about his background, and he was seen by a psychiatrist, who was convinced that his story was genuine. However, on the day of his transfer, the situation was radically altered by the receipt from his practitioner of summaries received from no fewer than thirty hospitals which the patient had visited since the beginning of 1964. In total, he had had three cystoscopies, ten intravenous pyelograms, and fifteen straight abdominal $X$-rays, and twenty-one midstream specimens of urine had been examined. All were normal. When confronted later with this evidence by the psychiatrist, he became very angry, saying that no-one was going to call him a liar, and is alleged to have punched the psychiatrist on $\omega$ the nose, breaking his spectacles. Shortly afterwards, $\frac{\text { ? }}{3}$ he was admitted for psychiatric treatment under compulsory order.

From the summaries one can follow his course $\frac{\mathbb{T}}{\mathbb{Q}}$ round the Home Counties, starting in the larger hospitals in the centre of London, travelling around its periphery, then down to Hampshire and Dorse, and finally to Oxford. Like many other cases $\overrightarrow{8} \overrightarrow{0}$ Munchausen's Syndrome (Galbraith, 1959), he wised chose to masquerade as a lorry driver, thus accountimg for his distant home address. All the hospitio admissions, apart from the first, occurred in 1964, ard o it is possible to trace the way in which he has gradually learnt to perfect his story. On the first admission, he was merely labelled a hysteric; on the next, he had a normal appendix removed, and $\mathbb{Q}$ for the subsequent three admissions his diagnosis was "abdominal pain, cause unknown". On each of the $\overrightarrow{\overrightarrow{0}}$ next 27 admissions, he successfully simulated renal 3 colic, and by the time he reached us, he was even passing bogus stones down the lavatory pan. As his perfected story fitted the classical concept of renal colic so perfectly, he gained easy admission. 흘 He never took his own discharge, and unlike other reported cases (Asher, 1951) showed few signs of the usual truculence. Perhaps aggression was allayed by frequent doses of pethidine.

Cases of Munchausen's Syndrome with symptoms such as M.T. manifested may escape 0 detection; renal colic does not compel surgery so no mass of tell-tale abdominal scars need be $\rightarrow$ present. Although I have not found other reports of this type of renal Munchausen's Syndrome $N$ in the literature, one wonders if one should therefore deduce that it is uncommon.

I am indebted to Dr. E. D. Acheson for permission to publish this case and for his advice, and to Dr. J. Cooke, Earlshilton, Leicester, for letting me make use of the summaries.

\section{REFERENCES}

ASHER, R. (1951): Munchausen's Syndrome, Lancet, T i, 339 .

GaLbRAith, H. J. (1959): Munchausen's Syndrome, Brit. med. J., ii, 664 . 